\title{
Inflammatory Markers: C-Reactive Protein, Erythrocyte Sedimentation Rate, and Leukocyte Count in Vitamin D Deficient Patients with and without Chronic Kidney Disease
}

\author{
Ibrahim Yildirim, ${ }^{1}$ Ender Hur, ${ }^{1}$ and Furuzan Kokturk ${ }^{2}$ \\ ${ }^{1}$ Division of Nephrology, Department of Internal Medicine, University of Bulent Ecevit, 67600 Zonguldak, Turkey \\ ${ }^{2}$ Department of Biostatistics, University of Bulent Ecevit, 67600 Zonguldak, Turkey
}

Correspondence should be addressed to Ibrahim Yildirim; breibrahim@yahoo.com

Received 4 April 2013; Accepted 9 June 2013

Academic Editor: Hulya Taskapan

Copyright (C) 2013 Ibrahim Yildirim et al. This is an open access article distributed under the Creative Commons Attribution License, which permits unrestricted use, distribution, and reproduction in any medium, provided the original work is properly cited.

\begin{abstract}
Although some studies revealed a positive relationship between vitamin $\mathrm{D}_{3}$ deficiency and inflammatory markers, there have been also many studies that failed to find this relationship. The aim of this large scaled study is to determine the association between the level of plasma 25 hydroxy vitamin $\mathrm{D}_{3}\left[25-(\mathrm{OH}) \mathrm{D}_{3}\right]$ and inflammatory markers in the general population without chronic kidney disease (CKD) and in patients with CKD. Participants with simultaneously measured inflammatory markers and 25-(OH) $\mathrm{D}_{3}$ levels were retrospectively analyzed $(n=1897)$. The incidence of all-cause inflammation infection, hospitalization, chronic renal failure, and vitamin B12 deficiency was evaluated. The medians of serum creatinine levels in subjects without renal failure were lower in 25- $(\mathrm{OH}) \mathrm{D}_{3}$ deficient group. Patients with $\mathrm{CKD}$ were more likely to have vitamin $\mathrm{D}_{3}$ deficiency compared with normal GFR. 25- $(\mathrm{OH}) \mathrm{D}_{3}$ levels were associated with a greater incidence of all-cause hospitalization, hypoalbuminemia, and vitamin $\mathrm{B} 12$ deficiency. However, there was no relationship between inflammatory markers and vitamin $\mathrm{D}_{3}$ levels. In $25-(\mathrm{OH}) \mathrm{D}_{3}$ deficient patients, inflammatory markers can be related to other inflammatory and infectious status such as malnutrition and cachexia. We believed that there must be a relationship between vitamin deficiency and inflammatory markers due to other causes than low 25- $(\mathrm{OH}) \mathrm{D}_{3}$ status.
\end{abstract}

\section{Introduction}

The deficiency of vitamin $\mathrm{D}_{3}$ is commonly associated with chronic kidney disease (CKD), and the prevalence of this hypovitaminosis increases as kidney function declines $[1,2]$. Several factors, such as aging, loss of appetite, and other factors affecting cutaneous synthesis, such as low sun exposure and skin pigmentations [3], have consistently been associated with low 25-hydroxyvitamin $\mathrm{D}\left[25-(\mathrm{OH}) \mathrm{D}_{3}\right.$ ] levels in the general population. Therefore, it is common in the elderly, malnourished individuals, and some societies [4].

Even though there is growing evidence to suggest that vitamin $\mathrm{D}_{3}$ status is associated with the development and progression of cardiovascular disease [5, 6], diabetes [7], and immune system disorders [8], there is limited information about the association of 25-(OH) $\mathrm{D}_{3}$ deficiency and inflammation in the general population without $\mathrm{CKD}$ and in patients with CKD.

Studies examining the association between low $25-(\mathrm{OH})$ $\mathrm{D}_{3}$ levels and inflammation infection are still popular. There are studies suggesting a relationship between a lack of vitamin $\mathrm{D}_{3}$ and morbidity and also mortality as well [9-12]. The results of these studies were contradictory and confusing. Randomized controlled trials of vitamin $\mathrm{D}_{3}$ supplementation have shown incompatible results, with some trials suggesting a decrease $[13,14]$ and other studies concluding no effect on inflammatory biomarkers [15].

The potential relationship between the deficiency of vitamin $\mathrm{D}_{3}$ and infection-inflammation remains poorly understood. Therefore, the aim of present study is to examine the 
TABLE 1: Demographical data.

\begin{tabular}{lc}
\hline & $n$ \\
\hline Patients with CKD & 340 \\
Gender (M/F) & $1897(377 / 1520)$ \\
Outpatient (\%) & $1717(90.5)$ \\
Hospitalized patient (all-cause) (\%) & $180(9.5)$ \\
The elderly group & \\
$\quad 65-74$ years & 320 \\
$75-84$ years & 209 \\
$>85$ years & 13 \\
\hline
\end{tabular}

CKD: chronic kidney disease; M: male; F: female; $n$ : the number of participants.

association between the level of plasma $25-(\mathrm{OH}) \mathrm{D}_{3}$ and inflammatory markers in the general population without chronic kidney disease and in patients with CKD.

\section{Methods}

2.1. Study Population. Present study was conducted between January 1, 2008 and April 25, 2012 in Bulent Ecevit University Hospital and 1897 patients with $25-(\mathrm{OH}) \mathrm{D}_{3}$ levels and inflammatory markers measured simultaneously were included. Patients whose age under 18 years, patients with primary hyperparathyroidism and hypoparathyroidism, were excluded. The study participants' age, gender, and hospitalization data were recorded. The clinical and laboratory data are shown in Tables 1 and 2. The relationship between 25-(OH) $\mathrm{D}_{3}$ levels and serum creatinine, parathormone $(\mathrm{PTH})$, sensitive C-reactive protein (CRP), erythrocyte sedimentation rate (ESR), leucocyte count, platelet count, and hemoglobin concentrations were evaluated as retrospectively in this study population.

Serum 25- $(\mathrm{OH}) \mathrm{D}_{3}$ levels vary depending on season; we categorized patients into two groups according to serum $25-(\mathrm{OH}) \mathrm{D}_{3}$ levels. Group 1 was composed of vitamin $\mathrm{D}_{3}$ deficient $(<10 \mu \mathrm{g} / \mathrm{L})$ population, and Group 2 was composed of vitamin $\mathrm{D}_{3}$ normal group $(>21 \mu \mathrm{g} / \mathrm{L})$. Patients with vitamin $\mathrm{D}_{3}$ levels between $10 \mu \mathrm{g} / \mathrm{L}$ and $20 \mu \mathrm{g} / \mathrm{L}$ were excluded from the analysis in order to avoid the effects of seasonal changes. So this intermediate group was not used in this study (Figure 1).

Patients with known levels of CRP were grouped categorically as normal (CRP $<6 \mathrm{mg} / \mathrm{L}$; there was no inflammation or infection) and as abnormal (CRP > $30 \mathrm{mg} / \mathrm{L}$; there was important inflammatory or infectious status). Likewise, to examine the relationship between renal failure and 25-(OH) $\mathrm{D}_{3}$ levels, participants were divided into categorical groups: the patients with and without renal failure. CKD was defined according to serum creatinine levels. Study cases with serum creatinine levels above $1.3 \mathrm{mg} / \mathrm{dL}$ for more than 3 months were considered as patients with CKD.

Moreover, the participants in this study were also divided into two groups: ambulatory patients and hospitalized patients.
TABLE 2: Clinical and laboratory data.

\begin{tabular}{lc}
\hline Variable $(n)$ & Mean \pm SD (Min-Max) \\
\hline Age $($ year $)(1897)$ & $55 \pm 15(18-90)$ \\
25-(OH) $D_{3}(\mu \mathrm{g} / \mathrm{L})(1897)$ & $16 \pm 13(3-201)$ \\
Vit B12 $(\mathrm{pg} / \mathrm{mL})(443)$ & $401.9(84-2001)$ \\
PTH $(\mathrm{pg} / \mathrm{mL})(1162)$ & $112 \pm 184(2-2500)$ \\
CRP $(\mathrm{mg} / \mathrm{L})(996)$ & $12.9 \pm 26.7(2-219)$ \\
ESR $(\mathrm{mm} / \mathrm{h})(1314)$ & $29 \pm 21.7(1-141)$ \\
WBC $\left(10^{3} / \mu \mathrm{g} / \mathrm{L}\right)(1451)$ & $7.7 \pm 3.5(2.6-100)$ \\
Hemoglobin $(\mathrm{gr} / \mathrm{dL})(1001)$ & $12.5 \pm 1.7(6.6-17.8)$ \\
Platelet $\left(10^{3} / \mu \mathrm{g} / \mathrm{L}\right)(1003)$ & $264 \pm 82(9-765)$ \\
Albumin $(\mathrm{gr} / \mathrm{dL})(577)$ & $4.13 \pm 0.58(1.6-5.0)$ \\
\hline
\end{tabular}

Vit B12: vitamin B12; PTH: parathormone; CRP: C-reactive protein; ESR: erythrocyte sedimentation rate; WBC: white blood cells; SD: standard deviation; Min: minimum; Max: maximum.

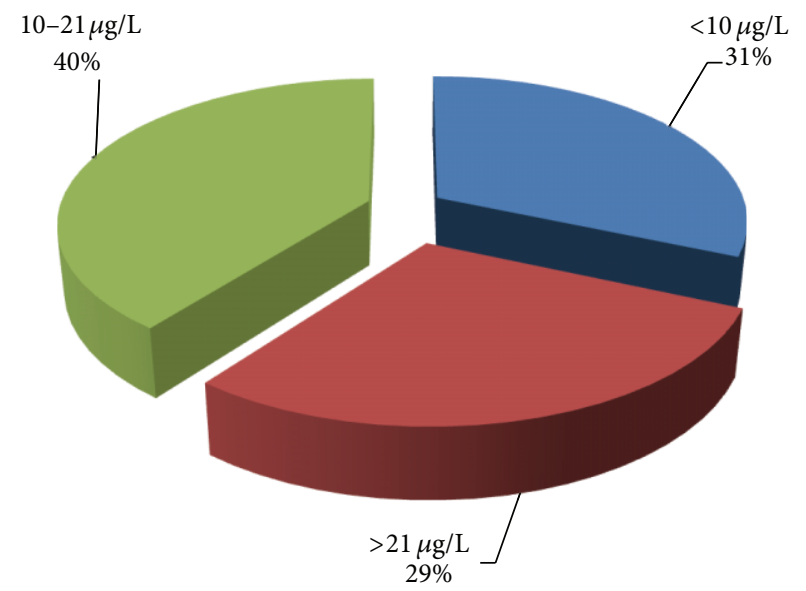

Figure 1: Distribution of 25- $(\mathrm{OH})$ vitamin $\mathrm{D}_{3}$ levels in study population.

Finally, vitamin $B 12$ levels were measured in vitamin $\mathrm{D}_{3}$ deficient and vitamin $\mathrm{D}_{3}$ normal group, and then these two groups were divided into subgroups of their own.

Primary endpoints are as follows:

(1) determining the 25- $(\mathrm{OH}) \mathrm{D}_{3}$ level in the general population and in patients with CKD;

(2) comparing the clinical and laboratory data regarding inflammation with levels of $25-(\mathrm{OH}) \mathrm{D}_{3}$;

(3) evaluation of whether low and normal 25- $(\mathrm{OH}) \mathrm{D}_{3}$ levels and inflammation could explain this potential association;

2.2. Biochemical Analysis. 25-Hydroxyvitamin $\mathrm{D}_{3}$ levels were measured by high performance liquid chromatographic analysis performed with using a Zivak HPLC system (Gebze, Turkey) using a commercial 25-OH vitamin $\mathrm{D}_{3}$ kit (Recipe, Munich, Germany). The reference values were $10-50 \mu \mathrm{g} / \mathrm{L}$ for winter, $20-120 \mu \mathrm{g} / \mathrm{L}$ for summer seasons. A deficiency in 25$(\mathrm{OH}) \mathrm{D}_{3}$ level was considered as below $10 \mu \mathrm{g} / \mathrm{L}$. 
TABlE 3: Vitamin $\mathrm{D}_{3}$ deficient and normal group medians in all outpatients participants.

\begin{tabular}{|c|c|c|c|c|c|}
\hline \multirow{2}{*}{ (Total number) } & \multicolumn{2}{|c|}{$25-(\mathrm{OH}) \mathrm{D}_{3}<9.9 \mu \mathrm{g} / \mathrm{L}$} & \multicolumn{2}{|c|}{$25-(\mathrm{OH}) \mathrm{D}_{3}>21 \mu \mathrm{g} / \mathrm{L}$} & \multirow{2}{*}{$P$} \\
\hline & $n$ & Median (Min-Max) & $n$ & Median (Min-Max) & \\
\hline Age $(n=1032)$ & 520 & $54(18-88)$ & 512 & $56(18-87)$ & 0.139 \\
\hline Albumin $(n=292)$ & 163 & $4.3(2.4-5)$ & 129 & $4.4(3-5)$ & $0.071^{*}$ \\
\hline $\operatorname{CRP}(n=554)$ & 262 & $3.6(3-204)$ & 283 & $3.5(2-156)$ & 0.943 \\
\hline Creatinine $(n=770)$ & 386 & $0.9(0.3-10)$ & 384 & $0.9(0.4-12)$ & 0.018 \\
\hline PTH $(n=655)$ & 335 & $72.8(3-1675)$ & 320 & $57(4-2269)$ & 0.000 \\
\hline $\operatorname{ESR}(n=716)$ & 353 & $23(2-131)$ & 363 & $23(2-109)$ & $0.204^{*}$ \\
\hline $\mathrm{WBC}(n=767)$ & 392 & $7.2(3.2-22.4)$ & 375 & $7.1(3.1-16.3)$ & 0.780 \\
\hline $\operatorname{Vitamin} \mathrm{B} 12(n=254)$ & 138 & $301(84-2001)$ & 116 & $336(111-1454)$ & 0.115 \\
\hline
\end{tabular}

CRP: C-reactive protein; ESR: erythrocyte sedimentation rate; WBC: white blood cells; Min: minimum; Max: maximum. ${ }^{*}$ When hospitalized patients included in the analysis; albumin and ESR gained significance $(P=0.001, P=0.024$, resp. $)$

Serum vitamin B12 and plasma PTH levels were measured with chemiluminescence method by Immulite 2000 (Diagnostic Products Corp., LA, USA).

PTH was measured by chemiluminescence with reference values of $16-87 \mu \mathrm{g} / \mathrm{L}$.

C-reactive protein was assayed with Dade Behring $\mathrm{BN}$ ProSpec System using a nephelometric method.

Serum albumin levels and ESR were measured by routine laboratory methods.

Leukocyte count, platelet count, and hemoglobin concentrations were measured by Beckman Coulter LH 780 hematology analyzer.

2.3. Statistical Analysis. Statistical analyses were performed by SPSS 18.0 software (SPSS Inc., Chicago, IL, USA). Distribution of data was determined by Kolmogorov-Smirnov test. Continuous variables were expressed as median (minimummaximum) and categorical variables as frequency and percent. Continuous variables were compared with the MannWhitney $U$ test and categorical variables were compared using Pearson's Chi-square test. Linear relation between two continuous variables was evaluated by Spearman correlation analysis. $P$ value of less than 0.05 was considered statistically significant for all tests.

\section{Results}

A total of 1897 subjects were included in this retrospective study. Patients that measured $25-(\mathrm{OH}) \mathrm{D}_{3}$ levels under $10 \mu \mathrm{g} / \mathrm{l}$ were $598(31.5 \%)$, the number of those between 10 and $21 \mu \mathrm{g} / \mathrm{L}$ was 751 (39.5\%), and the number of those over $21 \mu \mathrm{g} / \mathrm{L}$ was 550 (28.9\%), respectively, in the study group (Figure 1 ).

The difference between male and female in $25-(\mathrm{OH}) \mathrm{D}_{3}$ levels was statistically significant $(P<0.001)$, and $25-(\mathrm{OH})$ $\mathrm{D}_{3}$ levels were significantly lower in female [16.1 \pm 12.8 (3$121)]$ than in male $[19.2 \pm 12.9(3-201)]$. For this reason, male and female patients were divided into groups according to the presence of renal failure. The results are summarized in Tables 3 and 4.

There was no significant correlation between age and vitamin $\mathrm{D}_{3}$ deficiency in our study population. There were lower serum albumin levels in patients with vitamin $\mathrm{D}_{3}$ deficiency, but this was not statistically significant (Table 3). Median serum creatinine levels were less in patients with vitamin $\mathrm{D}_{3}$ deficiency without renal failure than in participants with normal vitamin $\mathrm{D}_{3}$ levels without renal failure (Table 4 ).

Serum albumin, CRP, ESR, and WBC levels had no significant relationship in groups that vitamin $\mathrm{D}_{3}$ deficiency and vitamin $\mathrm{D}_{3}$ normal in male and female patients without renal failure (Tables 1-4). There was no difference in the levels of albumin, CRP, ESR, and WBC in women with renal insufficiency, but there was significant difference between levels of serum albumin and ESR in male patients.

The inflammatory status measured by CRP showed no difference with respect to the $25-(\mathrm{OH}) \mathrm{D}_{3}(P=0.318)$.

In CRP variable that was categorized as $<6 \mathrm{mg} / \mathrm{L}$ and $\geq 6 \mathrm{mg} / \mathrm{L}$, there was no significant difference between CRP categories and $25-(\mathrm{OH}) \mathrm{D}_{3}$ levels $(P=0.728)$. The results are summarized in Table 5.

In CRP variable that was categorized as $<6 \mathrm{mg} / \mathrm{L}$ and $\geq 30 \mathrm{mg} / \mathrm{L}$, there was no significant difference between these CRP categories and 25- $(\mathrm{OH}) \mathrm{D}_{3}$ levels $(P=0.635)$ (Table 6).

Then, all participants were included in the study, both 25- $(\mathrm{OH}) \mathrm{D}_{3}$ and CRP variables taken as a numerical, and correlation analysis was performed. There was no correlation between the two groups $(r=-0.03, P=0.335)$.

The difference between men and women CRP levels was statistically significant $(P=0.013)$.

CRP and vitamin $\mathrm{D}_{3}$ levels in men and women were different; therefore, similar analyses were repeated in men and women groups. Median CRP in vitamin $\mathrm{D}_{3}$ deficient group and vitamin $\mathrm{D}_{3}$ normal group showed no significant difference in the male and female patients.

There was a weak positive correlation between age and CRP $(r=0.21, P<0.001)$.

When $25-(\mathrm{OH}) \mathrm{D}_{3}$ and $\mathrm{CRP}$ variables are taken as categorical variables and analyzing the relationships between variables, no significant correlation was found $(P=1.000)$.

The prevalence of vitamin $\mathrm{D}_{3}$ deficiency in patients with renal failure had a higher number $(P=0.000)$ (Table 6). This frequency were not statistically significant in male patients except advanced-stage renal failure (creatinine $<3.8 \mathrm{mg} / \mathrm{dL}$ ), $(P=0.148)$.

The frequency of vitamin D deficiency was evaluated between outpatient and hospitalized patients groups in this 
TABLE 4: (a) Vitamin $\mathrm{D}_{3}$ deficient and normal group medians in subjects without renal failure; (b) vitamin $\mathrm{D}_{3}$ deficient and normal group medians in subjects with renal failure.

(a)

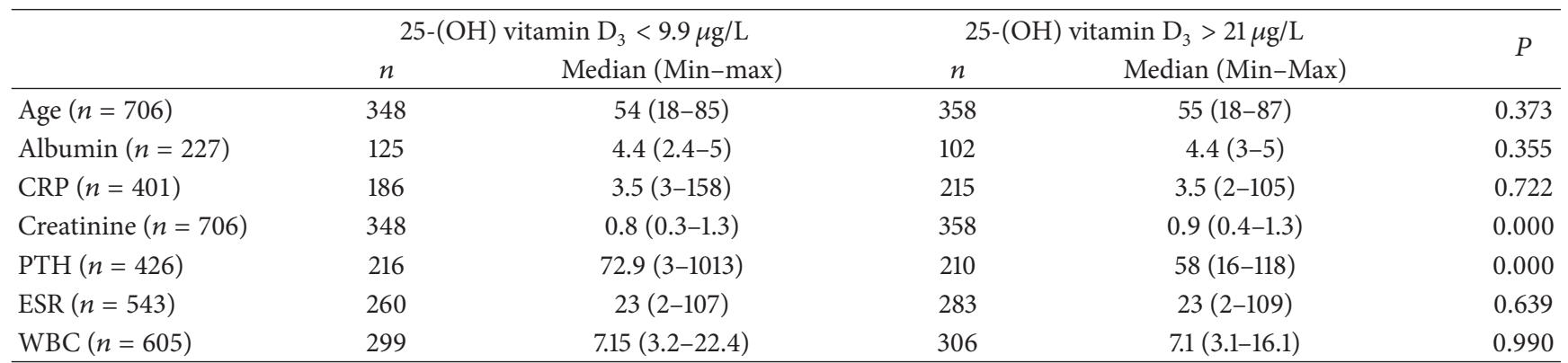

CRP: C-reactive protein; PTH: parathormone; ESR: erythrocyte sedimentation rate; WBC: white blood cells; Min: minimum; Max: maximum.

(b)

\begin{tabular}{|c|c|c|c|c|c|}
\hline & \multicolumn{2}{|c|}{$25-(\mathrm{OH}) \mathrm{D}_{3}<9.9 \mu \mathrm{g} / \mathrm{L}$} & \multicolumn{2}{|c|}{$25-(\mathrm{OH}) \mathrm{D}_{3}>21 \mu \mathrm{g} / \mathrm{L}$} & \multirow{2}{*}{$P$} \\
\hline & $n$ & Median & $n$ & Median & \\
\hline Age $(n=178)$ & 114 & $69(22-90)$ & 64 & $62.5(18-83)$ & 0.017 \\
\hline Albumin $(n=109)$ & 81 & $3.4(1.6-4.9)$ & 28 & $4.05(2.7-4.8)$ & 0.001 \\
\hline $\mathrm{CRP}(n=102)$ & 61 & $15(3-218)$ & 41 & $6(3-205)$ & 0.067 \\
\hline Creatinine $(n=178)$ & 115 & $2.1(1.4-13.6)$ & 63 & $1.75(1.4-12.4)$ & 0.289 \\
\hline $\operatorname{PTH}(n=121)$ & 77 & $194.5(6-2166)$ & 44 & $141(2-2269)$ & 0.161 \\
\hline $\operatorname{ESR}(n=106)$ & 63 & $48(2-131)$ & 43 & $33(8-141)$ & 0.003 \\
\hline $\mathrm{WBC}(n=144)$ & 97 & $8.4(0.1-44.4)$ & 47 & $7.6(3.7-21.7)$ & 0.641 \\
\hline
\end{tabular}

CRP: C-reactive protein; PTH: parathormone; ESR: erythrocyte sedimentation rate; WBC: white blood cells; SD: standard deviation; Min: minimum; Max: maximum.

TABLE 5: Vitamin $\mathrm{D}_{3}$ levels in patients with inflammation and without inflammation.

\begin{tabular}{lccc}
\hline & $n$ & $\begin{array}{c}25-(\mathrm{OH}) \mathrm{D}_{3} \\
\text { Median } \\
(\text { Min-Max })\end{array}$ & $\begin{array}{c}25-(\mathrm{OH}) \mathrm{D}_{3} \\
(\text { Mean } \pm \mathrm{SD})\end{array}$ \\
\hline $\mathrm{CRP}<6 \mathrm{mg} / \mathrm{dL}$ & 605 & $15(3-79)$ & $17.42 \pm 12.21$ \\
$\mathrm{CRP}>6 \mathrm{mg} / \mathrm{dL}$ & 390 & $15(3-201)$ & $17.47 \pm 15.65$ \\
\hline $\mathrm{CRP}$ total & 995 & $15(3-201)$ & $17.44 \pm 13.65$ \\
\hline
\end{tabular}

CRP: C-reactive protein; SD: standard deviation.

study population. The incidence of vitamin $\mathrm{D}_{3}$ deficiency in all-cause hospitalized patients was more frequent $(P=$ $0.000)$. The prevalence of vitamin $\mathrm{D}_{3}$ deficiency in outpatients was $46.3 \%(n=236)$ and in hospitalized patients was $67.5 \%$ $(n=77)$. The number of subjects with normal vitamin $\mathrm{D}_{3}$ was $53.7 \%$ for outpatients $(n=274)$ and for hospitalized patients was $32.4 \%(n=37)$, respectively (Table 6). Moreover age, ESR, WBC, and CRP medians had higher levels in hospitalized patients.

Finally, B12 levels were measured in 254 patients. The prevalence of low vitamin B12 $(<160 \mathrm{pg} / \mathrm{mL})$ was $68 \%$ ( $n=30)$, and the prevalence of normal vitamin B12 level $(>160 \mathrm{pg} / \mathrm{mL})$ was $32 \%(n=14)$ in the group with vitamin $\mathrm{D}_{3}$ deficiency, whereas the prevalence of low vitamin B12 was $51.4 \%(n=108)$, and the prevalence of normal vitamin B12 (Number 30$)$ was $48.6 \%(n=102)$ in the normal vitamin $\mathrm{D}_{3}$
TABLE 6: The frequency of CRP, vitamin B12, hospitalization, and renal failure in $25-(\mathrm{OH})$ vitamin $\mathrm{D}_{3}$ deficiency.

\begin{tabular}{lccc}
\hline & $25-(\mathrm{OH}) \mathrm{D}_{3}<$ & $25-(\mathrm{OH}) \mathrm{D}_{3}>$ & \multirow{2}{*}{$P$} \\
& $9.99 \mu \mathrm{g} / \mathrm{L}, n(\%)$ & $21 \mu \mathrm{g} / \mathrm{L}, n(\%)$ & \\
\hline $\mathrm{CRP}<6 \mathrm{mg} / \mathrm{dL}$ & $180(84.5)$ & $193(90.2)$ & \\
$\mathrm{CRP}>30 \mathrm{mg} / \mathrm{dL}$ & $33(15.5)$ & $21(9.8)$ & \\
Total & $\mathbf{2 1 3}$ & $\mathbf{2 1 4}$ & $\mathbf{0 . 7 7 0}$ \\
Vit B12 $<160 \mathrm{pg} / \mathrm{mL}$ & $33(21.7)$ & $15(12.4)$ & \\
Vit B12 $>160 \mathrm{pg} / \mathrm{mL}$ & $119(78.3)$ & $106(87.6)$ & \\
Total & $\mathbf{1 5 2}$ & $\mathbf{2 1 1}$ & $\mathbf{0 . 0 4 3}$ \\
Albumin $<3.5 \mathrm{~g} / \mathrm{dL}$ & $46(21)$ & $11(7.6)$ & \\
Albumin $>3.5 \mathrm{~g} / \mathrm{dL}$ & $173(79)$ & $133(92.4)$ & \\
Total & $\mathbf{2 1 9}$ & $\mathbf{1 4 4}$ & $\mathbf{0 . 0 0 1}$ \\
Outpatients & $520(87.1)$ & $513(93.3)$ & \\
Inpatients & $77(12.9)$ & $37(6.7)$ & \\
Total & $\mathbf{5 9 7}$ & $\mathbf{5 5 0}$ & $\mathbf{0 . 0 0 0}$ \\
With CKD & $115(24.8)$ & $63(15)$ & \\
Without CKD & $348(75.2)$ & $358(85)$ & \\
Total & $\mathbf{4 6 3}$ & $\mathbf{4 2 1}$ & $\mathbf{0 . 0 0 0}$ \\
\hline
\end{tabular}

CRP: C-reactive protein; CKD: chronic kidney disease.

group. Vitamin B12 deficiency was more frequently seen in patients with vitamin $\mathrm{D}_{3}$ deficiency $(P=0.043)$ (Table 6). 


\section{Discussion}

Present study did not reflect the true incidence of vitamin $\mathrm{D}_{3}$ deficiency because patients who are thought to lack of vitamin $\mathrm{D}_{3}$ were included in this study. A limited number of studies conducted in Turkey have shown that vitamin $\mathrm{D}_{3}$ deficiency is a common issue during the fall and winter in individuals, particularly for elderly. The deficiency of vitamin $\mathrm{D}_{3}$ is seen in $70-75 \%$ of women in our country. Vitamin $\mathrm{D}_{3}$ deficiency rates are $80-84 \%$ in the Middle East, $60-65 \%$ in Asia, $50-55 \%$ in Europe, and 50\% in Latin America [16-18]. Female constitutes the majority of patients may be due to less exposure to the sun and the higher prevalence of osteoporosis.

There was no significant correlation between age and vitamin $\mathrm{D}$ deficiency and that may be due to individual characteristics of the studied population. This relationship is shown in some other studies [11,19]. But many studies did not mentioned the relationship between age and vitamin $\mathrm{D}$ levels.

In present study we did not find a relationship between vitamin $\mathrm{D}_{3}$ deficiency and inflammatory markers, such as CRP, ESR, and leukocyte counts. Some other studies measured CRP was found the relationship but in these studies the relatively small number of participants were the limiting factor [20, 21]. In several studies were unknown accompanying diseases, and hospitalization rates $[9,22]$. There were no studies evaluating ESR, and leukocyte counts were evaluated in $25-(\mathrm{OH}) \mathrm{D}_{3}$ deficiency.

Sensitive CRP that was not measured is the limitation of the study. To resolve this drawback was categorized patients according to the levels of CRP. Therefore we divided our study populations into subsets according to CRP levels. Firstly, we counted the number of patients with and without vitamin $\mathrm{D}_{3}$ deficiency in CRP normal group. We found no significant difference between two subgroups. Secondly, we separated the study population into CRP normal and significantly high CRP groups. We found no significant difference between the last subgroups again. The reason for this classification was to evaluate the frequency of vitamin $\mathrm{D}_{3}$ deficiency in outpatients with important high level of CRP. Finally, we applied correlation analysis between the level of CRP and 25-(OH) $\mathrm{D}_{3}$. But a relationship between the level of CRP and 25- $(\mathrm{OH})$ $\mathrm{D}_{3}$ was not found in all our analyses. In other words, we did not observe an association between vitamin $\mathrm{D}$ deficiency and CRP levels anyway.

Patients' age, serum albumin, CRP, and ESR levels, leukocyte counts, and creatinine values were significantly different between ambulatory and hospitalized patients. The medians of inflammatory markers of hospitalized patients were higher compared to those of ambulatory patients except albumin levels. In addition, the frequency of $25-(\mathrm{OH}) \mathrm{D}_{3}$ deficiency was higher once again in hospitalized patients. These also mean that $25-(\mathrm{OH}) \mathrm{D}_{3}$ deficiency aggravates all-cause diseases, which is associated with the course of inflammation and infection but not CRP levels.

The prevalence of vitamin $\mathrm{D}_{3}$ deficiency in patients with CKD was more common at all stages in female patients; however, it was more common at advanced stage in male patients. This could be explained by a combination of factors, such as poor nutrition or a lack of skin synthesis due to low sun exposure [23]. In CKD patients, dietary restriction and loss of appetite due to uremia or high levels of fibroblast growth factor 23 may be stronger determining factors for 25$(\mathrm{OH}) \mathrm{D}_{3}$ deficiency.

In groups without renal failure, creatinine values of vitamin $\mathrm{D}_{3}$ deficient patients were lower than vitamin $\mathrm{D}_{3}$ normal subjects. Vitamin $\mathrm{D}_{3}$ deficient patients had higher PTH values. Higher PTH values were known and expected to be higher among the vitamin $\mathrm{D}_{3}$ deficient patients [23]. However, the low level of creatinine was not been described previously, and this difference was statistically significant.

In our study population, the levels of albumin were lower in vitamin $\mathrm{D}_{3}$ deficient patients than in vitamin $\mathrm{D}_{3}$ normal participations. However, this state did not reach statistical significance. This also pointed out other studies [24]. It has been reported decreased level of albumin in a large scaled study of Melamed et al. [9].

In groups without renal failure, low creatinine and albumin levels might be associated with a nutritional disorder or other comorbid inflammatory-infectious status. It is known that deficiency of vitamin $\mathrm{D}_{3}$ and malnutrition were related to each other. Some studies demonstrated that the replacement of vitamin $\mathrm{D}_{3}$ did not correct mortality [19]. Patients with high mortality despite treatment with vitamin $\mathrm{D}_{3}$ could have other disorders. To clarify this state we evaluated another vitamin such as vitamin B12. Vitamin B12 deficiency was more common in vitamin $\mathrm{D}_{3}$ deficient patients. Multivitamin deficiency was common in malnourished and elderly patients, but there was no study that tested vitamin B12 levels in vitamin $\mathrm{D}_{3}$ deficient patient in the literature.

For more accurate assessment it is necessary to know other factors that trigger inflammation and infection in studies examining the relationship between vitamin $\mathrm{D}$ and inflammatory markers. For example, when hospitalized patients are included in our analysis; all inflammatory markers gained significance statistically.

In addition, the reason for the deficiency of $25-(\mathrm{OH}) \mathrm{D}_{3}$ should be known in similar studies. However, there may be no relationship in encountered 25- $(\mathrm{OH}) \mathrm{D}_{3}$ deficiency due to low sunlight exposure, and it could be expected in patients with 25- $(\mathrm{OH}) \mathrm{D}_{3}$ deficiency due to malnutrition.

According to the results of our study, high levels of CRP in vitamin $\mathrm{D}$ deficient patients might be related to other factors such as infectious, inflammatory status, malnutrition, cachexia, or multivitamin deficiency. These factors and others may affect high morbidity and mortality in patients with vitamin $\mathrm{D}_{3}$ deficiency. Therefore, replacement of vitamin $\mathrm{D}$ alone could be corrected only in patients with vitamin D deficient patients in the foreground.

\section{Conflict of Interests}

The authors declare that they have no competing interests.

\section{Authors' Contribution}

Yildirim Ibrahim participated in concept, design, data collection, data analysis, data interpretation, and writing. Hur 
Ender participated in data interpretation and writing. Kokturk Furuzan participated in data analysis.

\section{Acknowledgment}

This study was funded by University of Bulent Ecevit.

\section{References}

[1] I. Rodríguez Villarreal, O. Ortega, P. Gallar et al., "Clinical and biochemical characteristics of predialysis patients in terms of 25 hydroxy vitamin D levels," Nefrologia, vol. 31, no. 2, pp. 185-191, 2011.

[2] K. J. Martin and E. A. González, "Vitamin D and the kidney," Missouri Medicine, vol. 109, no. 2, pp. 124-126, 2012.

[3] S. S. Sherman, B. W. Hollis, and J. D. Tobin, "Vitamin D status and related parameters in a healthy population: the effects of age, sex, and season," Journal of Clinical Endocrinology and Metabolism, vol. 71, no. 2, pp. 405-413, 1990.

[4] R. Alemzadeh and J. Kichler, "Parathyroid hormone is associated with biomarkers of insulin resistance and inflammation, independent of vitamin D status, in obese adolescents," Metabolic Syndrome and Related Disorders, vol. 10, no. 6, pp. 422-429, 2012.

[5] L. C. Y. Liu, A. A. Voors, D. J. van Veldhuisen et al., "Vitamin D status and outcomes in heart failure patients," European Journal of Heart Failure, vol. 13, no. 6, pp. 619-625, 2011.

[6] M. Cozzolino, M. Ketteler, and D. Zehnder, "The vitamin D system: a crosstalk between the heart and kidney," European Journal of Heart Failure, vol. 12, no. 10, pp. 1031-1041, 2010.

[7] Y. Echida, T. Mochizuki, K. Uchida, K. Tsuchiya, and K. Nitta, "Risk factors for vitamin D deficiency in patients with chronic kidney disease," Internal Medicine, vol. 51, no. 8, pp. 845-850, 2012.

[8] M. F. Holick, "Medical progress: vitamin D deficiency," New England Journal of Medicine, vol. 357, no. 3, pp. 266-281, 2007.

[9] M. L. Melamed, E. D. Michos, W. Post, and B. Astor, "25hydroxyvitamin D levels and the risk of mortality in the general population," Archives of Internal Medicine, vol. 168, no. 15, pp. 1629-1637, 2008.

[10] P. Autier and S. Gandini, "Vitamin D supplementation and total mortality: a meta-analysis of randomized controlled trials," Archives of Internal Medicine, vol. 167, no. 16, pp. 1730-1737, 2007.

[11] E. D. Michos, E. A. Streeten, K. A. Ryan et al., "Serum 25hydroxyvitamin D levels are not associated with subclinical vascular disease or C-reactive protein in the old order amish," Calcified Tissue International, vol. 84, no. 3, pp. 195-202, 2009.

[12] A. Zittermann, J. F. Gummert, and J. Börgermann, "Vitamin D deficiency and mortality," Current Opinion in Clinical Nutrition \& Metabolic Care, vol. 12, no. 6, pp. 634-639, 2009.

[13] S. S. Schleithoff, A. Zittermann, G. Tenderich, H. K. Berthold, P. Stehle, and R. Koerfer, "Vitamin D supplementation improves cytokine profiles in patients with congestive heart failure: a double-blind, randomized, placebo-controlled trial," American Journal of Clinical Nutrition, vol. 83, no. 4, pp. 754-759, 2006.

[14] G. van den Berghe, D. van Roosbroeck, P. Vanhove, P. J. Wouters, L. de Pourcq, and R. Bouillon, "Bone turnover in prolonged critical illness: effect of vitamin D," Journal of Clinical Endocrinology and Metabolism, vol. 88, no. 10, pp. 4623-4632, 2003.
[15] M. D. Witham, L. J. Crighton, N. D. Gillespie, A. D. Struthers, and M. E. T. McMurdo, "The effects of vitamin D supplementation on physical function and quality of life in older patients with heart failure a randomized controlled trial," Circulation: Heart Failure, vol. 3, no. 2, pp. 195-201, 2010.

[16] Z. Hekimsoy, G. Dinç, S. Kafesçiler et al., "Vitamin D status among adults in the Aegean region of Turkey," BMC Public Health, vol. 10, article 782, 2010.

[17] R. P. J. van der Wielen, M. R. H. Lowik, H. van dan Berg et al., "Serum vitamin D concentrations among elderly people in Europe," The Lancet, vol. 346, no. 8969, pp. 207-210, 1995.

[18] M.-H. Gannage-Yared, R. Chemali, N. Yaacoub, and G. Halaby, "Hypovitaminosis D in a sunny country: relation to lifestyle and bone markers," Journal of Bone and Mineral Research, vol. 15, no. 9, pp. 1856-1862, 2000.

[19] Ö. Ulutas and H. Taskapan, " $25(\mathrm{OH})$ vitamin D in patients with chronic kidney disease and dialysis patients," Türk Nefroloji Diyaliz ve Transplantasyon, vol. 21, no. 3, pp. 211-216, 2012.

[20] T. Eleftheriadis, G. Antoniadi, V. Liakopoulos, I. Stefanidis, and G. Galaktidou, "Inverse association of Serum 25hydroxyvitamin D with markers of inflammation and suppression of osteoclastic activity in hemodialysis patients," Iranian Journal of Kidney Diseases, vol. 6, no. 2, pp. 129-135, 2012.

[21] A. P. Ashraf, G. Fisher, J. Alvarez et al., "Associations of Creactive protein to indices of vascular health and the influence of serum 25(OH)D Status in Healthy Adults," Journal of Nutrition and Metabolism, vol. 2012, Article ID 475975, 6 pages, 2012.

[22] M. K. Shea, S. L. Booth, J. M. Massaro et al., "Vitamin K and vitamin D status: associations with inflammatory markers in the Framingham offspring study," American Journal of Epidemiology, vol. 167, no. 3, pp. 313-320, 2008.

[23] L. Y. Matsuoka, J. Wortsman, J. G. Haddad, P. Kolm, and B. W. Hollis, "Racial pigmentation and the cutaneous synthesis of vitamin D," Archives of Dermatology, vol. 127, no. 4, pp. 536-538, 1991.

[24] Y. Echida, T. Mochizuki, K. Uchida, K. Tsuchiya, and K. Nitta, "Risk factors for vitamin D deficiency in patients with chronic kidney disease," Internal Medicine, vol. 51, no. 8, pp. 845-850, 2012. 


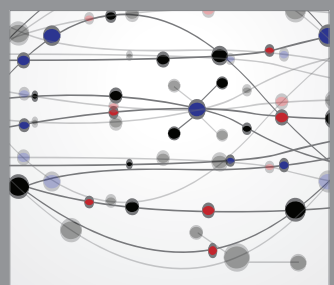

The Scientific World Journal
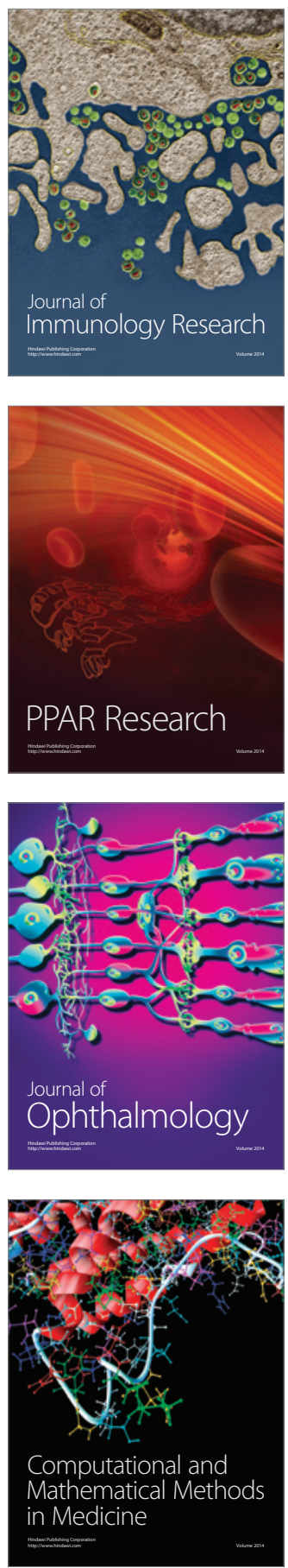

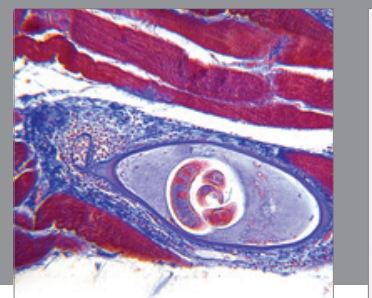

Gastroenterology

Research and Practice
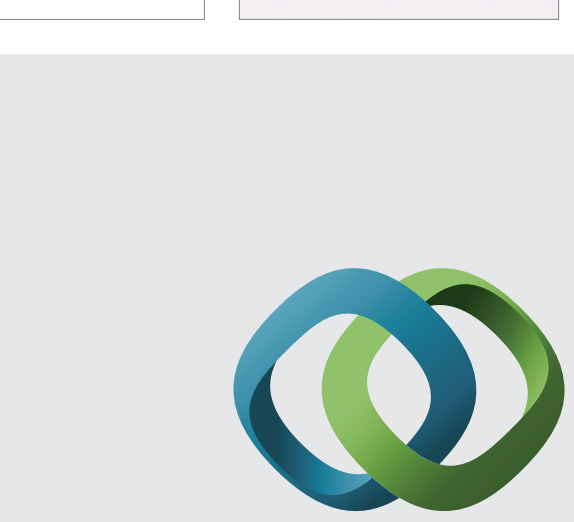

\section{Hindawi}

Submit your manuscripts at

http://www.hindawi.com
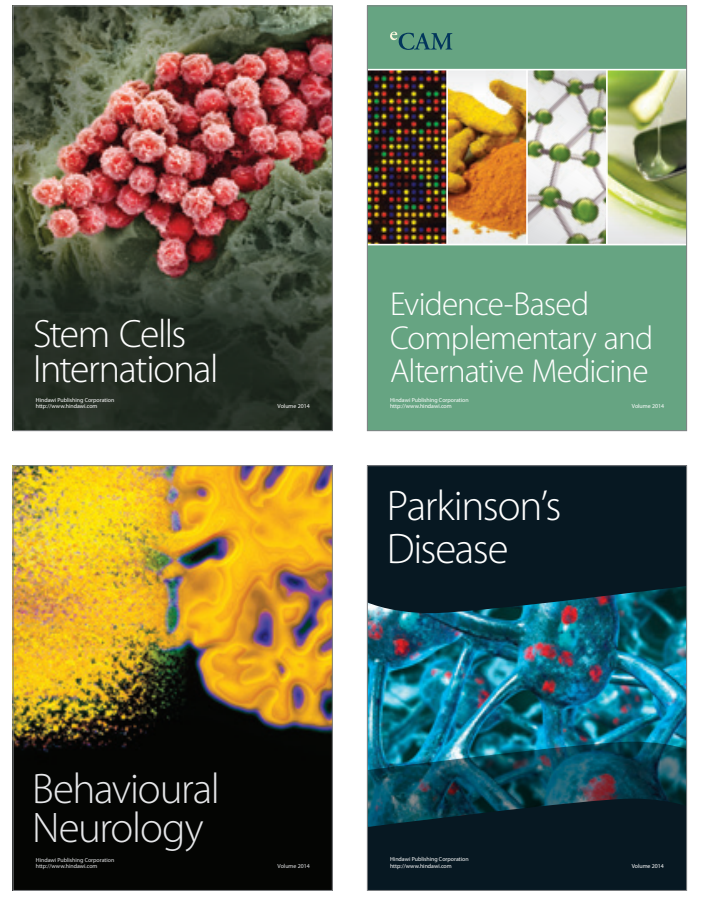
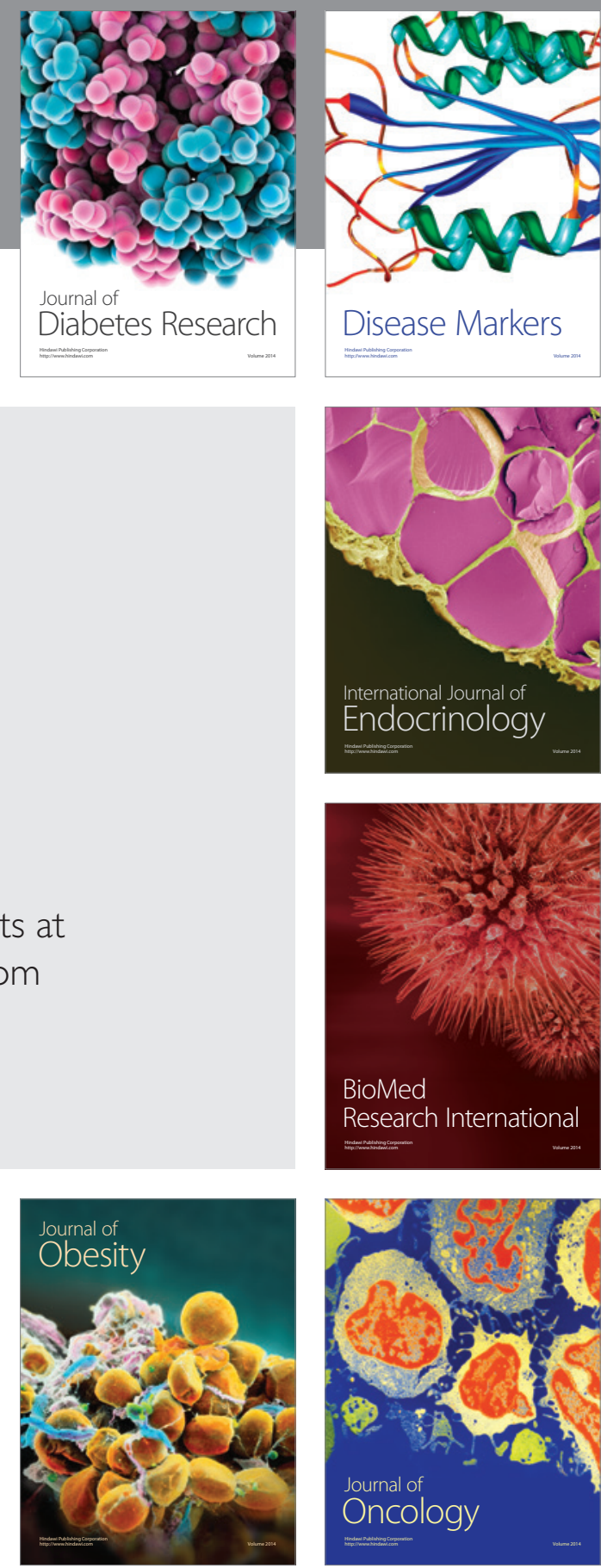

Disease Markers
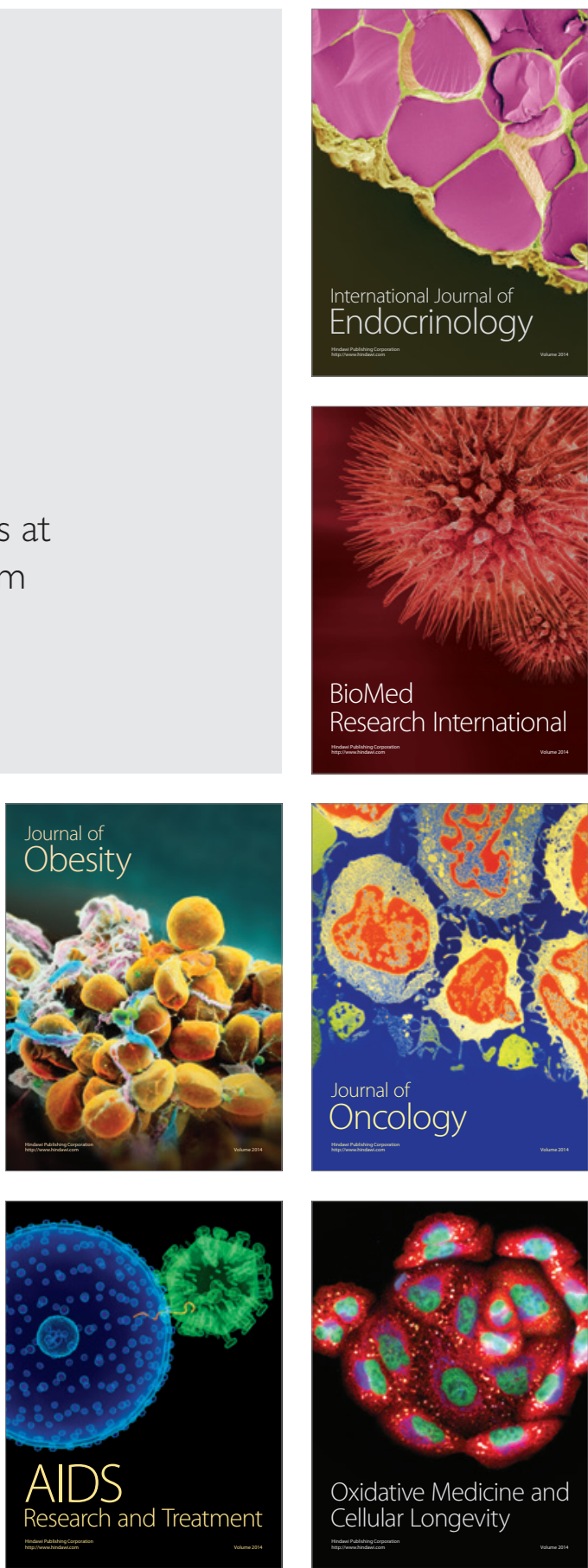